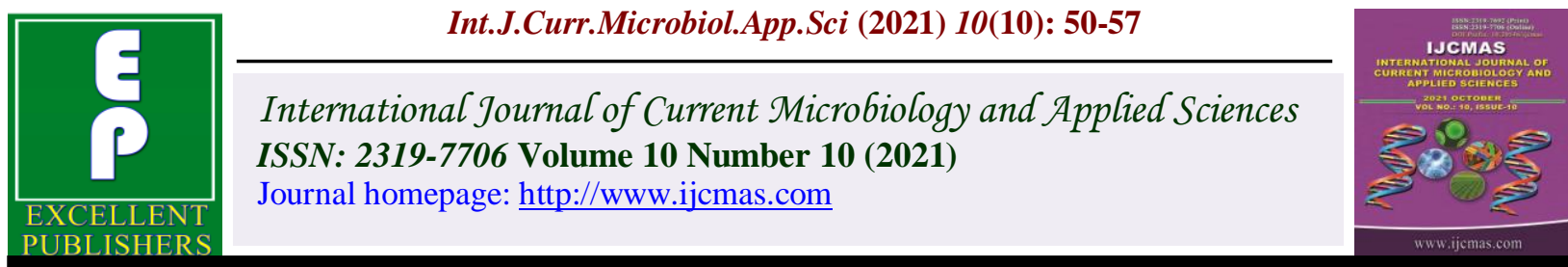

\title{
Antimicrobial Sensitivity Pattern and Incidence of Streptococcus agalactiae and other Pathogenic Microbial Organism from Pregnant Women at Tertiary Care Centre, Kanpur
}

\author{
Sugandh Rathore ${ }^{1}$ and Bitesh Kumar ${ }^{2 *}$ \\ Department of Microbiology, Autonomous State Medical College, \\ Firozabad, Uttar Pradesh, India \\ *Corresponding author
}

\section{Keywords}

Bacterial Vaginosis, Multigravida, Primigravida, Viginal swabs

\section{Article Info}

Accepted: 05 September 2021 Available Online: 10 October 2021

\section{A B S T R A C T}

This study was conducted in Rama Medical College Hospital \& Research Centre. The inclusion and exclusion criteria were applied. The study was conducted from January 2016 to December 2016. A total 50 high vaginal swabs were collected from pregnant women admitted to the labour room after gestation. Vaginal swabs collected from high vagina using sterile cotton swabs (Himedia, Mumbai) and transported to the laboratory and inoculated into enrichment broth, (Todd Hewitt Broth) and incubated at $37^{\circ} \mathrm{C}$ for 18-24 hours. After incubation sample were plated onto Blood agar and MacConkey agar (Himedia, Mumbai) and incubated aerobically at $37^{\circ} \mathrm{C}$ for 18-24 hours. The isolates were identified based on colony appearance, gram stain, and standard biochemical test obtained from (Himedia, Mumbai). Out of 50 women, $16(32 \%)$ were primigravida $34(68 \%)$ were multigravida. Number of pathogenic growth were 31 (62\%). The maximum number of aerobic vaginitis cases fell in the age group of 20-25 years followed by 26-30 and 30-35. The common pathogenic isolates in this study Candida, Escherichia coli, Klebsiella species, Coagulase negative Staphylococcus and Enterococcus species. The results of present study showed a high occurrence of Candida among pregnant women. There was a high prevalence of vaginal candidiasis among multigravida, women at the third trimester and those between age group 20 to 25 and 3 samples of aerobic vaginitis with polymicrobial growth. This study did not show any Group B Streptococcus. In this study were found most common sensitive drugs among all microbes- Gentamycin, Amikacin, Netilmicin, Amoxycillin/clavulanic acid, Piperacillin/tazobactam, Imipenem, Meropenem, Tigecycline, Colistin, Polymyxin B. Cotrimoxazole, Ceftriaxone, Ceftazidime, Cefoxitine, Teicoplanin, Levofloxacin, Vancomycin, Ampicillin, Penicillin, Tetracyclin, Aztreonam. 


\section{Introduction}

Group B streptococcus (GBS) or Streptococcus agalactaie is a gram-positive bacteria, it is one of the most common causes of neonatal morbidity and mortality in the worldwide. GBS causes infection in children and women but most common neonate colonized with GBS during birth (1).

The human body routinely harbours the bacteria which are collectively called normal or indigenous microbial species. They are widely distributed in various parts of the body, including eyes, skin, nails, oropharynx, gastrointestinal and genital tracts (2). Microbial infections of the vagina in pregnant woman can pose serious problems because they can lead to medical complications such as preterm labour, amniotic fluid infection, premature rupture of the fetal membranes, and low birth weight of the neonates, leading to high prenatal mortality. The vagina could be infected by a variety of pathogens including bacteria, fungi, viruses and parasites $(3,4)$.

Bacterial Vaginosis (BV) is the commonest cause of vaginal discharge of women of childbearing years in the western world. Enterobacteriaceae is the leading cause of the genital tract infection, which includes Escherichia coli, Klebsiella species, Proteus species, Enterobacter species, etc. These organisms are mainly from the external genitalia, vagina, genital tract, rectum and gastro-intestinal tract. Escherichia coli accounts for $80-90 \%$ in primary infections and $70-80 \%$ in recurrent infections it is also the most common aerobe to be harboured in the gut of humans. Escherichia coli is a normal inhabitant of the vagina and is seen to colonize upto $20 \%$ of pregnant women which has been reported as a risk for very low birth weight delivery and other perinatal complications (5). Staphylococcus aureus has also been reported as a causative factor, although on a small scale, for chorioamnionitis and neonatal sepsis in pregnancy (6). Vulvovaginal candidiasis is also called Candidal vaginitis or monilial infection of the vulva which is caused by overgrowth of candida species, most commonly Candida albicans, Candida glabrata and Candida tropicalis characterised by curd like vaginal discharge, itching, erythema, burning, irritation of vulva and vagina usually odourless with dysuria and dyspareunia $(7,8)$. Pregnant women are more vulnerable to VVC than healthy women with chronic recurrent candidiasis (9). Vulvovaginal candidiasis is an important cause of morbidity in pregnancy which can cause abortion, Candida chorioamnionitis, subsequent preterm delivery, emotional stress and suppression of immune system $(10,11)$.

The aim of this study was to evaluate the antimicrobial sensitivity pattern and incidence of Streptococcus agalactiae and other pathogenic microbial organism from pregnant women.

\section{Materials and Methods}

This study was done from January to December 2016 conducted in the Department of Microbiology, Rama Medical College, Hospital and Research Centre, Kanpur, India. Ethical clearance taken by Institutional Ethical Committee. A total of 50 High vaginal swabs from pregnant women were collected.

\section{Inclusion Criteria}

All pregnant women (Primigravida and Multigravida) admitted to the labour room after $35 \pm 1$ week of gestation were included in this study.

\section{Exclusion Criteria}

A detailed obstetric history was taken especially to identify the risk factors for 
bacterial and fungal colonization. Those women with history of intake of antibiotics during the past two weeks and pre-existing medical disorders complicating pregnancy and women who had undergone pelvic examination prior to vaginal swab were excluded from the study.

\section{Study Procedure}

Vaginal swabs were collected from high vagina using sterile cotton swab (Himedia, Mumbai). The swabs were immediately placed into transport media (Himedia, Mumbai) and transported to the laboratory at room temperature within 5-6 hours. The samples were plated on Blood agar and MacConkey agar (HiMedia, Mumbai) and incubated aerobically at $37^{\circ} \mathrm{C}$ for $24-48$ hours. The isolates were identified based on colony appearance, gram stain and standard biochemical tests. All media for biochemical tests were obtained from HiMedia, Mumbai, India. Fungal isolates were further identified by subculture on Hichrome media (HiMedia, Mumbai). Antibiotic sensitivity test of isolates were performed on Mueller Hinton agar plate (HiMedia, Mumbai, India) by Kirby-Bauer disk diffusion method following the National Committee for Clinical Laboratory Standards Interpretative (CLSI) guidelines 2016. Following the antimicrobial agents were used for Tetracycline $30 \mathrm{mcg}$, Cotrimoxazole 25 $\mathrm{mcg}$, Gentamycin $50 \mathrm{mcg}$, Amikacin $30 \mathrm{mcg}$, Netilmycin $30 \mathrm{mcg}$, Ciprofloxacin $10 \mathrm{mcg}$, Ofloxacin $2 \mathrm{mcg}$, Amoxicillin/clavulannic acid $30 \mathrm{mcg}$, Piperacillin/tazobactam 100 $\mathrm{mcg} / 10 \mathrm{mcg}$, Ceftriaxone $30 \mathrm{mcg}$, Ceftazidime $30 \mathrm{mcg}$, Cefoperazone/salbactam $75 / 30 \mathrm{mcg}$, Cefotaxime $30 \mathrm{mcg}$, Aztreonam $30 \mathrm{mcg}$, Imipenem $10 \mathrm{mcg}$, Meropenem $10 \mathrm{mcg}$, Tigecycline $15 \mathrm{mcg}$, colistin $10 \mathrm{mcg}$, Polymyxin B $300 \mathrm{mcg}$, Teicoplanin $30 \mathrm{mcg}$, Levofloxacin $5 \mathrm{mcg}$, Penicillin $10 \mathrm{mcg}$, Ampicillin $10 \mathrm{mcg}$, and Vancomycin $30 \mathrm{mcg}$. Standardized inoculum adjusted to 0.5
McFarland standard tubidity of each isolate were inoculated onto Mueller-Hinton agar (MHA) plates using a sterile cotton swab by streaking the swab over the entire surface three times. Sterile forceps were used to place the appropriate antibiotic disks on the inoculated plate. The plates were incubated aerobically at $37^{\circ} \mathrm{C}$ overnight, and then tests were read. The control strain was tested each time when susceptibility testing was performed. Test results were only validated in the cases where inhibition zone diameters of control strains were with in performance ranges in accordance with CLSI guidelines (12).

\section{Results and Discussion}

A total of 50 high vaginal swabs were collected from pregnant women admitted to the labour room after $35 \pm 1$ week of gestation. The prevalence of microorganisms in this study was $62 \%$. The study group included was in the reproductive age between 20-35 years, shows the distribution of age. Out of 50 women, $16(32 \%)$ were Primigravida and 34 (68\%) were Multigravida. The maximum number of aerobic vaginitis cases fell in the age group of $20-25$ years $(54 \%)$, followed by 26-30 (40\%) and 30-35 (6\%) (Table-1). The number of pathogenic growth showed in (Figure-1). The most common etiological agent of aerobic vaginitis in this study were found Candida species (30\%)- C. albicans (7), C. tropicalis (3) C. glabrata (1), C. krusei (4) followed by Escherichia coli (18\%), Klebsiella species (8\%), Caogulase negative Staphylococcus (4\%) and Enterococcus (2\%) (Table-2) (Figure-2). The age wise distribution of pathogenic growth shows (Table-3). Out of 31 , three samples of aerobic vaginitis with polymicrobial growth, each with two microorganisms. Combination of Klebsiella oxytoca and Candida species, a combination of Escherichia coli and coagulase negative Staphylococcus and another Escherichia coli 
and Candida species (Fig-2). Antibiotic sensitivity pattern of gram positive bacteria isolates from high vaginal swabs of pregnant women showed in (Table-4,5).

Present study revealed that several species of microbes are responsible for vaginal infection among females. Vaginal discharge is one of the most frequent gynaecological problems encountered in females especially during their reproductive stage (13). Pregnant women have a two fold increase in the prevalence of vaginal microorganisms colonization compared to non-pregnant women. Increased levels of circulating estrogen's and deposition of glycogen and other substrates in the vagina during pregnancy influence this association. The present study showed a prevalence of pathogenic bacteria of 31 (62\%), comparison to another study conducted by Isibor et al., who showed a prevalence of (74.7\%) (13). Another study conducted by AnyodohNwadike S O et al., showed a low prevalence of $(40.1 \%)$ (14), very less prevalence rates were seen by Battikhi MN et al., show (32.3\%) and Onyemelukwe, et al., (12.7\%) $(15,16)$.

In the present study, Candida species (30\%) was predominantly isolated fungus followed by the bacterial isolates. Among them Escherichia coli (18\%) were predominant followed by Klebsiella species (8\%), Coagulase negative Staphylococcus (4\%) and Enterococcus species (2\%), Similar pattern of organism was reported by Battikhi et al., and Abdelaziz, et al., Candida species were predominantly found showing prevalence rate of $(16.6 \%)$ and $(34.1 \%)$ respectively $(15,17)$. However, Kumar G et al., found Escherichia coli to be the most common isolate followed by Candida species (18). The high prevalence rate of Candida species observed in this study is an indication that Candida species is becoming a leading aetiology of the reproductive tract infections in women of child bearing age. In the present study, coagulase negative Staphylococcus was (4\%), but a higher prevalence rate has been reported by Battikhi M N et al., (8.2\%) and S. Baka I et al., $(5.4 \%)(15,19)$.

The present study, Enterococcus species (2\%) were found, it is in accordance with the study by Anyodoh-Nwadike S O et al., (4.7\%) (14). Out of 31 pathogenic isolates, three were showed polymicrobial growth each with two isolates. Similar results were seen by Nahar, et al., (2016) (20).

In this study, most of the females were 20-25 years of age group (54\%) which is also supported by Ibrahim et al., (2014) in which 20-24 years was the most common age group affected (21). However, in a study conducted by Nahar et al., (2014) most common age group was affected 26-30 years (20).

A 21-30 years was also the most common age group affected seen by $\mathrm{Z}$ A Abdelaziz et al., (2014) (17). In present study, bacterial vaginitis was more common in multigravida (68\%) as compare to primigravida (32\%)., this is in accordance with the previous study by Ibrahim et al., and Mitima et al., $(21,22)$. This may be due to high coital frequency which leads to reduction in the physiological barrier in the vagina as result of overgrowth of normal commensals occurs.

In this study, all the nine isolates of Escherichia coli were $100 \%$ sensitive to aminoglycosides group of drugs, which is quite high as compare to the study by Sylvia $e t$ al., (2015) in which sensitivity to gentamycin was $(50.3 \%)$ (14). These were fairly sensitive to fluroquinolone group and cephalosporin group of drugs. However, higher sensitivity were seen for these drugs (99.3\%) and also sensitivity were seen to Carbapenems group specially Imipenem (100\%) which seen by Battikhi et al., (15). 
Table.1 Age wise distribution of multigravida and primigravida.

\begin{tabular}{|c|c|c|c|}
\hline S. No. & Age group & $\begin{array}{c}\text { Primigravida } \\
\text { n (\%) }\end{array}$ & $\begin{array}{c}\text { Multigravida } \\
\text { n (\%) }\end{array}$ \\
\hline 1. & $20-25$ & $12(24 \%)$ & $15(30 \%)$ \\
\hline 2. & $26-30$ & $4(8 \%)$ & $16(32 \%)$ \\
\hline 3. & $31-35$ & 0 & $3(6 \%)$ \\
\hline 4. & Total & $16(32 \%)$ & $34(68 \%)$ \\
\hline
\end{tabular}

Table.2 Distribution of aerobic organisms isolated from pregnant woman.

\begin{tabular}{|c|c|c|}
\hline S.no. & Aerobic Organisms isolated & $\begin{array}{c}\text { No. of pregnant female } \\
\mathbf{n}(\boldsymbol{\%})\end{array}$ \\
\hline $\mathbf{1}$ & Candida & $15(30 \%)$ \\
\hline $\mathbf{2}$ & Escherichia coli & $9(18 \%)$ \\
\hline $\mathbf{3}$ & Klebseilla species & $4(8 \%)$ \\
\hline $\mathbf{4}$ & Caugulase negative staphylococcus & $2(4 \%)$ \\
\hline $\mathbf{5}$ & Enterococcus faecalis & $1(2 \%)$ \\
\hline
\end{tabular}

Table.3 Age wise distribution of pathogenic isolates.

\begin{tabular}{|c|c|c|c|c|}
\hline Bacterial species & $\mathbf{2 0 - 2 5}$ years & $\mathbf{2 6 - 3 0}$ years & $\mathbf{3 1 - 3 5}$ year & Total \\
\hline Candida & 5 & 10 & 0 & 15 \\
\hline Escherichia coli & 8 & 1 & 0 & 9 \\
\hline Klebsiella pneumoniae & 0 & 2 & 0 & 2 \\
\hline Klebsiella oxytoca & 1 & 1 & 0 & 2 \\
\hline CONS & 1 & 1 & 0 & 2 \\
\hline Enterococcus & 0 & 0 & 1 & 1 \\
\hline
\end{tabular}

Table.4 Antibiogram (\% sensitivity) of Gram negative bacterial isolates from High vaginal swabs of pregnant women.

\begin{tabular}{|c|c|c|c|c|c|c|c|c|c|c|c|c|c|c|c|c|c|c|}
\hline BACTERIA & AMC & $\begin{array}{c}\text { CT } \\
\mathbf{R}\end{array}$ & $\begin{array}{c}\text { CA } \\
\text { Z }\end{array}$ & $\begin{array}{c}\text { CF } \\
\text { S }\end{array}$ & $\begin{array}{l}\text { CT } \\
\mathrm{X}\end{array}$ & $\begin{array}{l}\mathbf{A} \\
\mathbf{T}\end{array}$ & $\begin{array}{l}\mathbf{C I} \\
\mathbf{P}\end{array}$ & $\begin{array}{l}\mathbf{O} \\
\mathbf{F}\end{array}$ & $\begin{array}{c}\text { CO } \\
\text { T }\end{array}$ & $\begin{array}{c}\text { GE } \\
\mathbf{N}\end{array}$ & $\begin{array}{l}\mathbf{A} \\
\mathbf{K}\end{array}$ & $\begin{array}{c}\text { NE } \\
\text { T }\end{array}$ & TE & $\begin{array}{c}\text { TG } \\
\text { C }\end{array}$ & $\begin{array}{c}\text { IM } \\
\mathbf{P}\end{array}$ & $\begin{array}{l}\text { M } \\
\text { RP }\end{array}$ & $\begin{array}{l}\mathbf{C} \\
\mathbf{L}\end{array}$ & $\begin{array}{l}\mathbf{P} \\
\mathbf{B}\end{array}$ \\
\hline $\begin{array}{c}\text { Escherichia } \\
\text { coli }(\mathbf{n}=9)\end{array}$ & 44.4 & $\begin{array}{c}77 . \\
7\end{array}$ & $\begin{array}{c}66 . \\
6\end{array}$ & $\begin{array}{c}77 . \\
7\end{array}$ & $\begin{array}{c}66 . \\
6\end{array}$ & $\begin{array}{c}88 . \\
8\end{array}$ & $\begin{array}{c}66 . \\
6\end{array}$ & $\begin{array}{c}66 . \\
6\end{array}$ & $\begin{array}{c}77 . \\
7\end{array}$ & $\begin{array}{c}99 . \\
9\end{array}$ & $\begin{array}{c}99 . \\
9\end{array}$ & $\begin{array}{c}99 . \\
9\end{array}$ & $\begin{array}{c}66 . \\
6\end{array}$ & $\begin{array}{c}99 . \\
9\end{array}$ & $\begin{array}{c}99 . \\
9\end{array}$ & $\begin{array}{c}88 . \\
8\end{array}$ & $\begin{array}{c}99 . \\
9\end{array}$ & $\begin{array}{r}99 \\
.9\end{array}$ \\
\hline $\begin{array}{c}\text { Klebsiella } \\
\text { oxytoca }(\mathrm{n}=2)\end{array}$ & 0 & 0 & 0 & 0 & 0 & 0 & 0 & 0 & 0 & 100 & $\begin{array}{c}10 \\
0\end{array}$ & $\begin{array}{c}10 \\
0\end{array}$ & 50 & 100 & $\begin{array}{c}10 \\
0\end{array}$ & 50 & $\begin{array}{c}10 \\
0\end{array}$ & $\begin{array}{c}10 \\
0\end{array}$ \\
\hline $\begin{array}{c}\text { Klebsiella } \\
\text { pneumoniae } \\
(\mathrm{n}=2)\end{array}$ & 50 & 100 & 100 & $\begin{array}{c}10 \\
0\end{array}$ & 100 & 50 & 50 & 50 & 50 & 100 & $\begin{array}{c}10 \\
0\end{array}$ & $\begin{array}{c}10 \\
0\end{array}$ & $\begin{array}{c}10 \\
0\end{array}$ & 100 & $\begin{array}{c}10 \\
0\end{array}$ & 100 & $\begin{array}{c}10 \\
0\end{array}$ & $\begin{array}{c}10 \\
0\end{array}$ \\
\hline
\end{tabular}


Table.5 Antibiogram of Gram positive Bacteria.

\begin{tabular}{|c|c|c|c|c|c|c|c|c|c|}
\hline Bacteria & P-G & CX & AMC & LE & TE & AK & GEN & VA & TEI \\
\hline $\begin{array}{c}\text { MRCONS } \\
(\mathbf{n}-1)\end{array}$ & 0 & 0 & 0 & 0 & $100 \%$ & - & - & $100 \%$ & $100 \%$ \\
\hline $\begin{array}{c}\text { MSCONS } \\
(\mathbf{n}-1)\end{array}$ & $100 \%$ & $100 \%$ & $100 \%$ & $100 \%$ & $100 \%$ & - & - & $100 \%$ & $100 \%$ \\
\hline $\begin{array}{c}\text { Enterococcus } \\
(\mathbf{n}-1)\end{array}$ & $100 \%$ & - & $100 \%$ & $100 \%$ & $100 \%$ & $100 \%$ & 0 & $100 \%$ & $100 \%$ \\
\hline
\end{tabular}

Fig.1 Number of swabs which showed pathogenic growth were $(n=31)$.

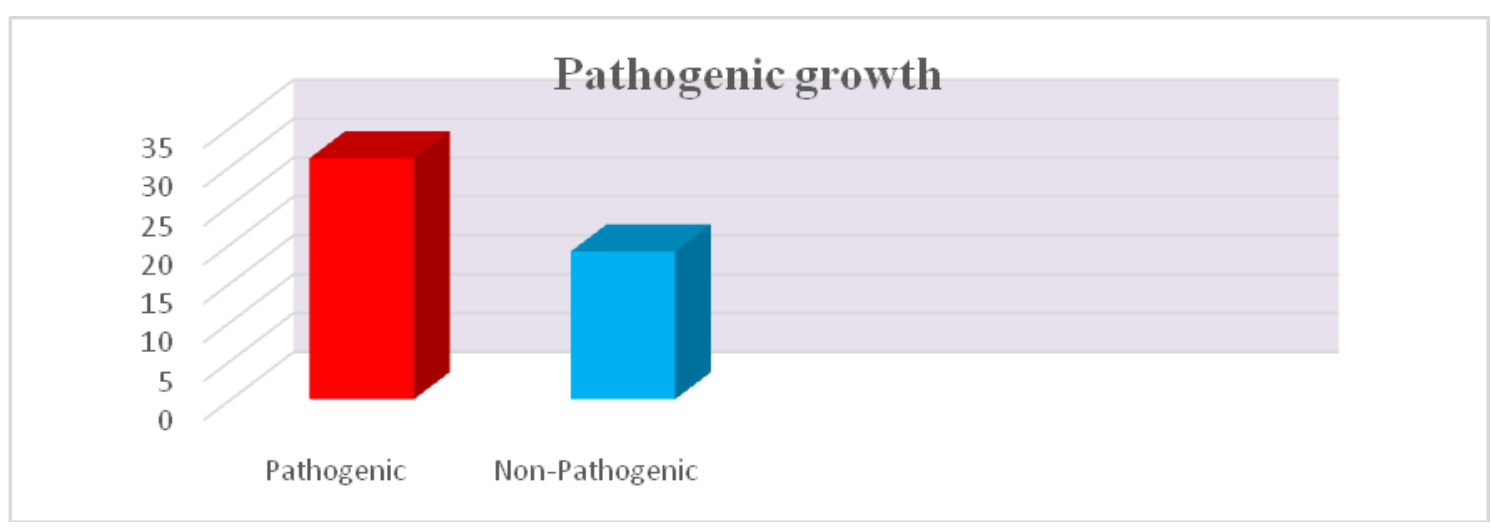

Fig.2 Distribution of Polymicrobial isolates in aerobic vaginitis in pregnancy.

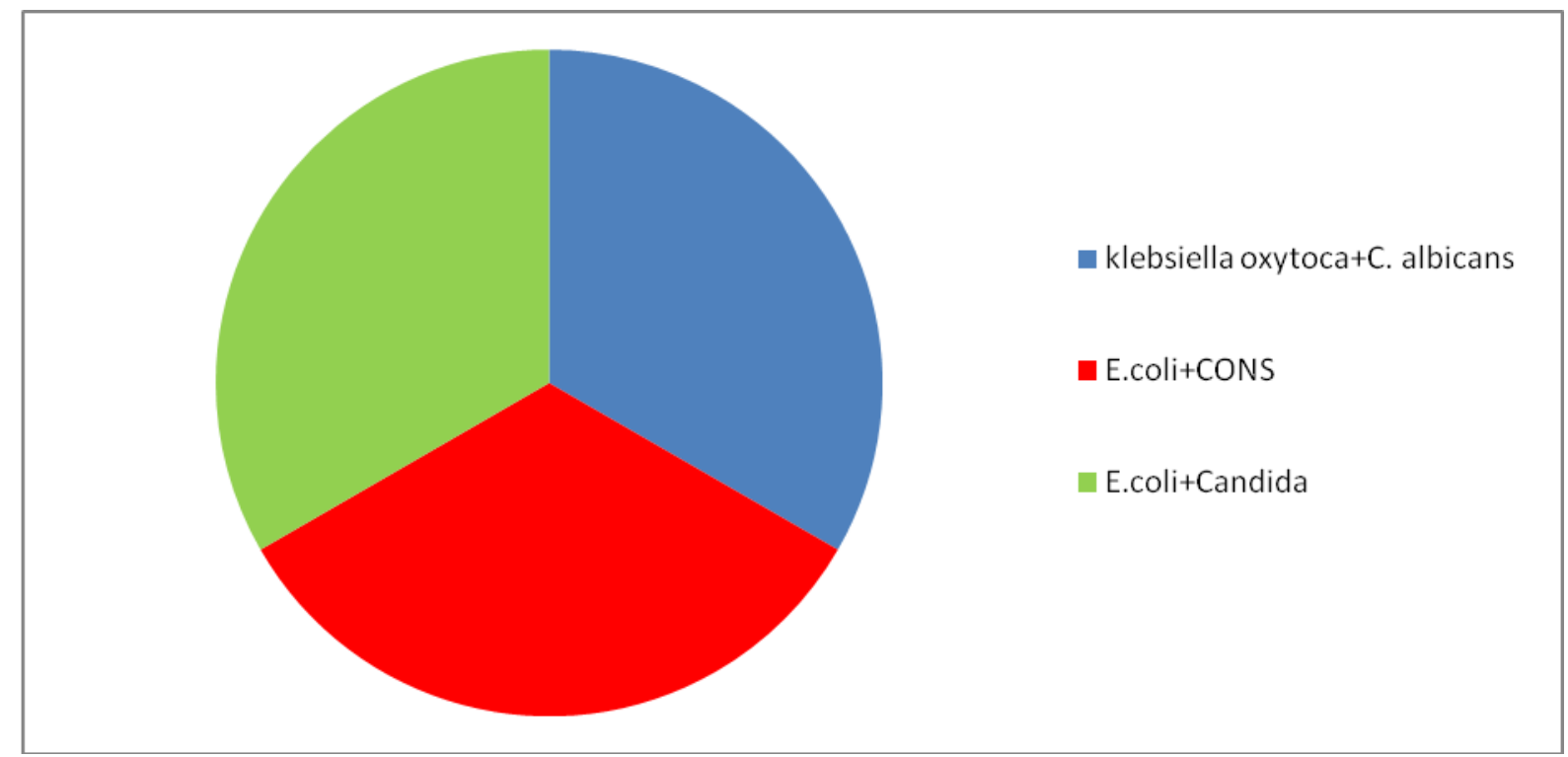

The isolates of Klebsiella oxytoca were $100 \%$ sensitive to aminoglycosides, imipenem, tigecycline, colistin and polymyxin B. High resistance were seen for fluroquinolones, cephalosporins and meropenem. The isolates of Klebsiella pneumonia were $100 \%$ sensitive to most of the drugs except fluoroquinolones. Where high resistance were seen, similar 
pattern was reported by Battikhi et al., (15).

In the present study Enterococcus isolated was (100\%) sensitive to vancomycin and beta lactam group of drugs, fluroquinolones groups of drugs and animoglycosides and(100\%) sensitivity to vancomycin was seen but high resistance were seen for beta lactams, fluoroquinolones. In present study CONS isolated were $(100 \%)$ sensitive to vancomycin $(50 \%)$ levofloxacin and $(50 \%)$ to amoxicillin, this is also similar by Nahar et al., (20).

\section{Limitations}

As the resources are limited and short time, small sample size selected for this study. In the present study, did not found Group B Streptococcus. So, more sample size studies are needed.

In conclusion, vaginal discharge is one of the most frequent gynaecological problems encountered in females especially in pregnant women. Candida species was the predominant pathogen observed in this study. Known predisposing factors for symptomatic vaginal discharge are poor hygiene, low socioeconomic status, early sexual activity and multiple partners. Routine vaginal swabs samples culture should be performed on all pregnant women during prenatal visits, especially during the second and third trimesters. In the present study concluded that several species of microbes including fungal and bacterial are responsible for vaginal infection among pregnant women's. Due to the emergence of multidrug resistance isolates, the clinicians should follow strict guidelines in prescribing antimicrobial drugs. Apart from treatment patient awareness and education is the most important and effective step.

\section{Acknowledgment}

Authors gratefully thank to their Head of the
Department, Associate Professor and colleagues for excellent guidance and support.

\section{References}

1. Woods C J, Masri I. Group B streptococcus (GBS) Infections. Medscape. https://emedicine.medscape.com/article/22 9091-overview

2. Fierer $\mathrm{N}$, Ferrenberg $\mathrm{S}$, Flores $\mathrm{G} \mathrm{E}$, Gonzalez A, Kueneman J, Legg T, et al., From animalcules to an ecosystem: application of ecological concepts to the human microbiome. Annu Rev Ecol Evol Syst.2012;43:137-55.

3. Giraldo P C, Araujo E D, Junior J E, do Amaral R L, Passos M R, Goncalves A K. The prevalence of urogenital infection in pregnant women experiencing preterm and full term labor. Infect Dis Obstet Gynecol. 2012;(1064-7449):878241.

4. Dover S E, Aroutcheva A A, Faro S, Chikindas M L. Natural antimicrobials and their role in vaginal health: a short review. Int J Probiotics. 2008;3(4):219-230.

5. Dasari S, Anandan S K, Rajendra W, Valluru L. Role of microbial flora in female genital tract: A comprehensive review. Asia Pacific Journal of Tropical Disease. 2016;6(11):909-917.

6. Stanley C N, Ugboma H A A, Ibezim E C, Attama A A. Prevalence Antibiotic Susceptibiliy of Staphylococcus Aureus and Other Staphylococcal infections in pregnant women Attending Antenatal Clinic in a Tertiary Hospital in Port Harcourt, Nigeria. J Infect Dis Ther. 2013;125(1):2332-77.

7. Akinbami N A, Babalola O G, Shittu O M, Tijani M A, Adekola A S. Detection and Epidemiology of Vulvovaginal Candidiasis among Asymptomatic Pregnant Women Attending a Tertiary Hospital in Ogbomoso, Nigeria. Int. J. Biomed. Res. 2015;6(07):18-23.

8. Nviriesy P. Vulvovaginal Candidiasis and bacterial vaginosis infections. North Am. J. 
Clin. Dis. 2008;22:637-652.

9. Mitchell H. Vaginal Discharge-Causes, Diagnosis and Treatment. Biomed J. 2004;328:1306-1308.

10. Sobel J D. Vaginitis. The New England Journal of medicine. 1997;337(26):18961903.

11. Singh S I. Treatment of Vulvovaginal Candidiasis. Clin. J. Rev. 2003;136(9): 2630.

12. CLSI Performance standard for Antimicrobial Susceptibiliy testing; twenty fourth informational supplement CLSI document M100-S26. Wayne, PA clinical Laboratory Standard Institute; 2016. https://clsi.org/standards/products/microbio $\log$ /documents/m100

13. Isibor $\mathrm{J} \mathrm{O}$, Samuel $\mathrm{S} \mathrm{O}$, Nwaham $\mathrm{C} \mathrm{I}$, Amanre I N, Igbinovia O, Akhile A O. Prevalence of bacterial and candida albicans infection amongst women attending Irrua Specialist Teaching Hospital, Irrua, Nigeria. African J Microb Res. 2011;5(20):3126-3130.

14. Anyodoh-Nwadike S O, Okorondu S I, C. Obiajuru I O, Nwadike P O, Nwaokorie F $\mathrm{O}$, Akerele $\mathrm{J}$ O. Comparative study of the prevalence and Antibiogram of bacterial isolates from the urinary and genital tract of antenatal patients. J Pharm Biol Scie. 2015;10(1)15-19.

15. Battikhi M N, Batikkhi Q G. Prevalence and drug susceptibility of microorganism isolated from urinary and genital tracts of pregnant women in Jordan. EC Microbiology. 2015;2(2):269-277

16. Onyemelukwe N F, Obi S N, Ozumba B C. Significant bacteriuria in pregnancy in Enuhun, Nigeria. $\mathbf{J}$ of
Medicine.2003;8(2):20-22.

17. Abdelaziz Z A, Ibrahim M I, Bilal N E, Hamid M E. Vaginal infections among pregnant women at Omdurman Maternity hospital in Khartoum, Sudan. J Infect Dev Ctries. 2014;8(4):490-497.

18. Kumar G, Singh K. Microbial profile of High vaginal swab from symptomatic women of Reproductive Age group: Data from Tertiary care Hospital. Int J Sci. Res. 2013;6(14)2319-7064.

19. S. Baka, I. Tsirmpa, E. Saltaoura, A. Chasiakou, S. Hassiakou, V. Gennimata, E. Kouskouni. Prevalence of aerobic vaginitis among different age group of symptomatic patients.https://www.escmid.org/escmid_p ublications/escmid_elibrary/material/?mid= 16167

20. Nahar D, Soni G, Chand A E, Mourya S. Bacterial etiology and their antibiogram in aerobic vaginitis patients at tertiary care hospital, kota rajasthan. International Journal of Scientific Study. 2016;4(3):103107.

21. S M Ibrahim, M Bukar, G B Galadima, B M Audu, H M Ibrahim. Prevalence of bacterial vaginosis in pregnant women in Maiduguri, North- Eastern Nigeria. Nigerian $J$ of Clin Practice. 2014;17(2):154-158.

22. Kashosi T Mitima, Steve Ntamako, Achippe M Birindwa, Ntakwinja Mukanire, John M Kivukuto, et al., Prevalence of colonization by Streptococcus agalactiae among pregnant women in Bukavu, Democratic Republic of the Congo. J infect Dev. Ctries 2014;8(9):1195-1200.

\section{How to cite this article:}

Sugandh Rathore and Bitesh Kumar. 2021. Antimicrobial Sensitivity Pattern and Incidence of Streptococcus agalactiae and other Pathogenic Microbial Organism from Pregnant Women at Tertiary Care Centre, Kanpur. Int.J.Curr.Microbiol.App.Sci. 10(10): 50-57. doi: https://doi.org/10.20546/ijcmas.2021.1010.008 